\title{
Iatrogenic Pharmacological Toxicity Resulting in First Indian Lawsuit for Medical Malpractice Insights: 20yrs Old Youth with Femur Fracture, Dies of Prescribed Opioid Overdose in Hospital
}

\section{Vivekanshu Verma $^{1 *}$ and Santosh Kumar Verma ${ }^{2}$}

${ }^{1}$ Associate Consultant, Emergency and Trauma Care, Medanta-The Medicity, Gurugram, India

${ }^{2}$ Senior Advocate, Rajasthan High Court, India

*Corresponding Author: Vivekanshu Verma, Associate Consultant, Emergency and Trauma Care, Medanta-The Medicity, Gurugram, India.

Received: April 03, 2019; Published: June 04, 2019

DOI: $10.31080 /$ ASPS.2019.03.0297

\begin{abstract}
Iatrogenic poisoning caused by prescribing/administration errors or unrecognised adverse drug interactions has been identified as a significant problem, and these account for about $1 \%$ of calls to the National Poisons Information Service. In India, medical malpractice suits first appeared in courts with regularity beginning in the 1990s, after Consumer Protection act included medical services. However, before the 1960s, legal claims for medical malpractice were rare, and had little impact on the practice of medicine. We are describing one of the first malpractice lawsuit, which involved fatal iatrogenic toxicity. Overall in-hospital mortality rates are less than $0.5 \%$. The challenge for the attending clinician is to identify as early as possible patients who are at risk of developing serious clinical toxicity.

Keywords: Toxicity; Fracture; Hospital
\end{abstract}

Facts

20yrs old youth suffered femur fracture due to trauma, received first aid and shifted to Poona Hospital in taxi with wooden rods support tied on broken limb to Poona 200 miles away, in a taxi after a journey of about eleven hours, by his father, who was also doctor. Orthopaedics admitted patient and advised urgent shifting to OT for treatment of fracture, gave Morphine as analgesic without anaesthetic, attempted manual reduction and traction of Femur Fracture for one hour. Patient brought out of OT, remained unconscious and had breathing difficulty $2 \mathrm{hrs}$ later, went into respiratory failure and eventually died $4 \mathrm{hrs}$ later during resuscitation [1].

\section{Plaintiff}

You made multiple attempts for about an hour to reduce my fracture, used excessive manual force in OT, and gave me opioid overdose during ortho procedure, failed to monitor me during narcosis, ignored my abnormal shallow breathing during unconscious state and didn't secured my airway timely, resulting in compromised airway, lack of oxygen supply, causing hypoxic damage to vital centres of my brain, resuscitation initiated only after my father (who was also a doctor) raised the alarm.
Defense

I have not done any reduction of your fracture but had merely provided immobilisation with light traction and given morphine on advise of my senior Ortho consultant, for relieving your pain during traction in Operation theatre. Although my consultant advised to give two injections of morphine to you in OT, but I have given only one to you, thus it's not an overdose. And as per my observation, I have documented cause of death (without post-mortem) as Cerebral Fat Embolism due to long bone fracture, as it may have occurred due to circulation of fat globules released from bone marrow of broken femur, thus blocking the supply of oxygen to vital area of brain.

Result

Patient's father filed lawsuit of alleged medical negligence against Hospital and doctor - Court held them negligent - Liable to pay damages under Fatal Accidents act, 1855 - Monetary Compensation of Rs 3000/- to the patient's father [2].

\section{Toxicokinetics}

Opiates are a group of naturally occurring compounds derived from the juice of the poppy Papaver somniferum. Morphine is the 
classic opiate derivative used widely in medicine. The term opioids refers to these and other derivatives of naturally occurring opium (eg, morphine, heroin, codeine, and hydrocodone) as well as new, totally synthetic opiate analogs (eg, fentanyl, butorphanol, meperidine, and methadone. Opioids share the ability to stimulate a number of specific opiate receptors in the CNS, causing sedation and respiratory depression. Death results from respiratory failure, usually as a result of apnea or pulmonary aspiration of gastric contents. In addition, acute noncardiogenic pulmonary edema may occur by unknown mechanisms.

The toxic dose varies widely, depending on the specific compound, the route and rate of administration, and tolerance to the effects of the drug. Usually, peak effects occur within 2-3 hours, but absorption may be slowed by the pharmacologic effects of opioids. Some patients have been found to be rapid metabolizers of codeine (to morphine through the hepatic enzyme CYP2D6), which may increase the risk for acute intoxication. Diagnosis is simple when typical manifestations of opiate intoxication are present (pinpoint pupils and respiratory and CNS depression) and is confirmed when the patient quickly awakens after administration of naloxone. Maintain an open airway and assist ventilation if necessary. Administer supplemental oxygen and Naloxone [3].

\section{Discussion}

The court held them guilty of negligence and wrongful acts on the following grounds:

- The Clinical notes did not justify the reasons doctor has stated for delaying his treatment of unconsciousness or surgical reduction of fracture.

- $\quad$ Nowhere in the case history had doctor mentioned that that he had given only one injection of morphine, instead of two. When asked during cross exam about two injections, doctor told that he has given only one injection, and he forgot to give second injection of morphine.

- Doctor's plea that fat embolism must have set in right from time of the accident or on account of inadequate immobilisation and hazards of long journey in taxi, was not justified as there was no mention of this in the clinical notes, nor any symptoms nor signs were mentioned which occur many hours prior to setting of pulmonary symptoms, nor did he warned patient's father of this risk of embolism.

- The letter exchanged between doctor and patient's father later, clearly stated that he had done fracture reduction.

\section{Conclusion}

A person who holds himself out ready to give medical advice and treatment impliedly holds forth that he is possessed of skill and knowledge for the Purpose [4]. Such a person when consulted by a patient, owes certain duties, namely, a duty of care in deciding whether to undertake the case, a duty of care in deciding what treatment to give, and a duty of care in the administration of that treatment. A breach of any of these duties gives a right of action of negligence against him. The medical practitioner has a discretion in choosing the treatment which he proposes to give to the patient and such discretion is wider in cases of emergency, but, he must bring to his task a reasonable degree of skill and knowledge and must exercise a reasonable degree of care according to the circumstances of each case.

\section{Conflict of interest}

$\mathrm{Nil}$

\section{Bibliography}

1. Judgement Citation: Supreme Court of India decision in Laxman Balkrishna Joshi vs Trimbak Bapu Godbole And Anr. AIR 1281969 SCR (1969) 206.

2. Singh J and Bhushan B. "Medical Negligence and Compensation". 4th Ed. Bharat Law Publications. (2018): 840.

3. Olson K. "Poisoning and Drug Overdose". 6th Ed. McGrawHills. (2018).

4. Koley TK. "Medical Negligence and the Law in India". 1st Ed. Oxford University Press. (2010): 278.

Volume 3 Issue 7 July 2019

(C) All rights are reserved by Vivekanshu Verma and Santosh Kumar Verma. 